COMP concentrations was analyzed using a mixed-effects regression model (Random effects: individuals, visits and COMP measurement time points).

Results: $28 \mathrm{RA}$ and $22 \mathrm{ACPA}+$ patients participated in this prospective study. Table 1 summarizes patient demographics and outcome measures. Serum COMP levels increased in response to the walking exercise in both groups but the acute response was not different in RA patients compared to ACPA+ individuals. Higher physical activity level by IPAQ was associated with higher overall COMP concentration. Doubling of total physical activity is associated with an increase in serum concentration of $0.32 \mathrm{U} / \mathrm{L}(95 \% \mathrm{Cl} 0.09$ to $0.54, \mathrm{p}=0.006)$. ACPA+ individuals but not RA patients show an association between serum COMP concentration and physical activity duration (Figure 1).

Table 1. Summary of subject characteristics and outcome measures.

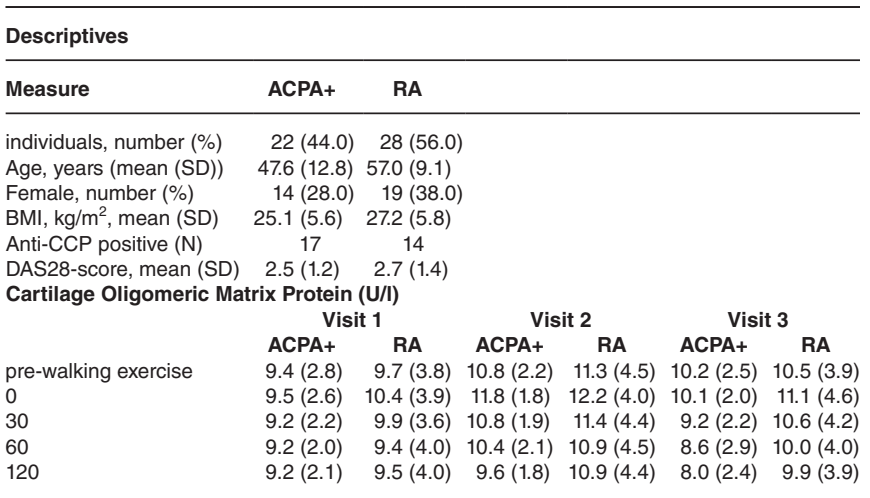

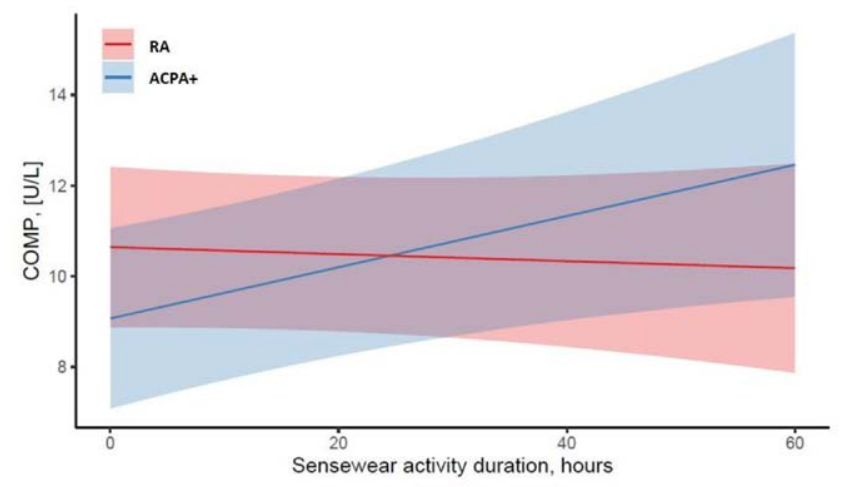

Figure 1. Estimated marginal mean COMP by physical activity duration for RA and ACPA+.

Conclusion: Pre-exercise serum COMP concentration is similar in ACPA+ and RA and shows a similar increase in response to walking in both groups. Physical activity duration appears to influence serum COMP concentration in ACPA+. Given that acute COMP release was not different between ACPA+ and RA while overall COMP values are associated with physical activity level, the discrepancy between ACPA+ and RA for this association can be explained by reduced vigor or qualitative differences in physical activity.

Disclosure of Interests: Lisa Bleckwedel-Rolack: None declared, Koray Tascilar: None declared, Veronika Nees: None declared, Julia Hühne: None declared, Axel Hueber: None declared, Jürgen Rech Speakers bureau: Abbvie, Biogen, BMS, Chugai, GSK, Lilly, MSD; Mylan, Novartis, Roche, Sanofi, Sobi, UCB, Consultant of: Abbvie, Biogen, BMS, Chugai, GSK, Lilly, MSD; Mylan, Novartis, Roche, Sanofi, Sobi, UCB, Grant/research support from: Novartis, Sobi, Georg Schett Speakers bureau: Lilly, Novartis, Consultant of: Lilly, Novartis, Gilead, BMS, Abbvie, Grant/ research support from: Lilly, Novartis, Arnd Kleyer Speakers bureau: Lilly, Novartis, Consultant of: Lilly, Novartis, Gilead, BMS, Abbvie, Grant/research support from: Lilly, Novartis, Anna-Maria Liphardt Speakers bureau: Mylan, Paid instructor for: Abbvie, Consultant of: MEDA Pharma, Grant/research support from: Novartis DOI: 10.1136/annrheumdis-2021-eular.1527

\section{POS0382 EXPANSION OF CD4+/CD8+ DOUBLE-POSITIVET CELLS IS ASSOCIATED WITH A SEVERE DISEASE COURSE IN RHEUMATOID ARTHRITIS}

P. Nguyen ${ }^{1}$, K. Rothe ${ }^{1}$, M. Melzer ${ }^{1}$, M. Krasselt ${ }^{1}$, M. Pierer ${ }^{1}$, U. Wagner ${ }^{1}$. ${ }^{1}$ Leipzig University Hospital, Rheumatology, Leipzig, Germany

Background: $\mathrm{CD}^{+} / \mathrm{CD}^{+}$double-positive $\mathrm{T}(\mathrm{dpT})$ cells are a set of pathologic $\mathrm{T}$ cells, representing about $1 \%$ of peripheral blood T cells and increasing with age in healthy individuals. Patients with rheumatoid arthritis (RA) more frequently have expanded dpT cells compared to age-matched controls, up to a frequency of $8 \%$ [1]. However, whether dpT cell expansion harbors clinical significance in RA is not known.

Objectives: The goal of the study was to assess possible associations of DPT expansion with clinical features of patients with RA.

Methods: In this cross-sectional study, dpT cells were measured in RA patients $(n=70)$ via fluorescence-activated flow cytometry. Clinical data including age, sex, disease duration, treatment history, disease activity parameters, and radiographic structural damage was collected. Radiographs of hands and feet were used to determine the modified Sharp/van der Heijde (SvdH) score. Expansion of dpT cells was defined as a frequency of $>2 \%$ of the total $T$ cell pool, based on reference ranges determined in a large cohort of healthy individuals [2]. Mann-Whitney-U test was used to compare groups and $X^{2}$ test was used for contingency tables. Statistical analyses were conducted using GraphPad Prism v8 (GraphPad Software, San Diego, USA).

Results: DpT cells were expanded in more than a quarter of our cohort $(n=19$, $27.1 \%)$. Patients with expanded dpT cells more often used biologics or targeted synthetic DMARDs than patients with low dpT cells ( $68.4 \%$ vs. $38 \%, p=0.02)$. Radiographic damage was also significantly worse in patients with DPT expansion, as shown in their higher SvdH score (median 24.5 vs. 6, $p=0.008$ ) and its component scores for erosion (median 19 vs. $0, p=0.004$ ) and joint space narrowing (median 8 vs. $2, p=0.017$ ) (figure $1 \mathrm{~A}$ ). There was no difference regarding sex, age, disease duration, seropositivity and disease activity between the groups (figure 1B).

Conclusion: DpT cell expansion is associated with higher scores of radiographic structural damage despite more frequent use of highly effective therapeutics. An expansion of dpT cells is not uncommon in RA, and affected patients represent a subset at high risk for a more severe disease course.

\section{REFERENCES:}

[1] Quandt D, Rothe K, Scholz R, et al. Peripheral CD4CD8 Double Positive T Cells with a Distinct Helper Cytokine Profile Are Increased in Rheumatoid Arthritis. PLOS ONE 2014;9:e93293. doi:10.1371/journal.pone.0093293

[2] Apoil PA, Puissant-Lubrano B, Congy-Jolivet N, et al. Reference values for T, B and NK human lymphocyte subpopulations in adults. Data Brief 2017;12:400-4. doi:10.1016/j.dib.2017.04.019
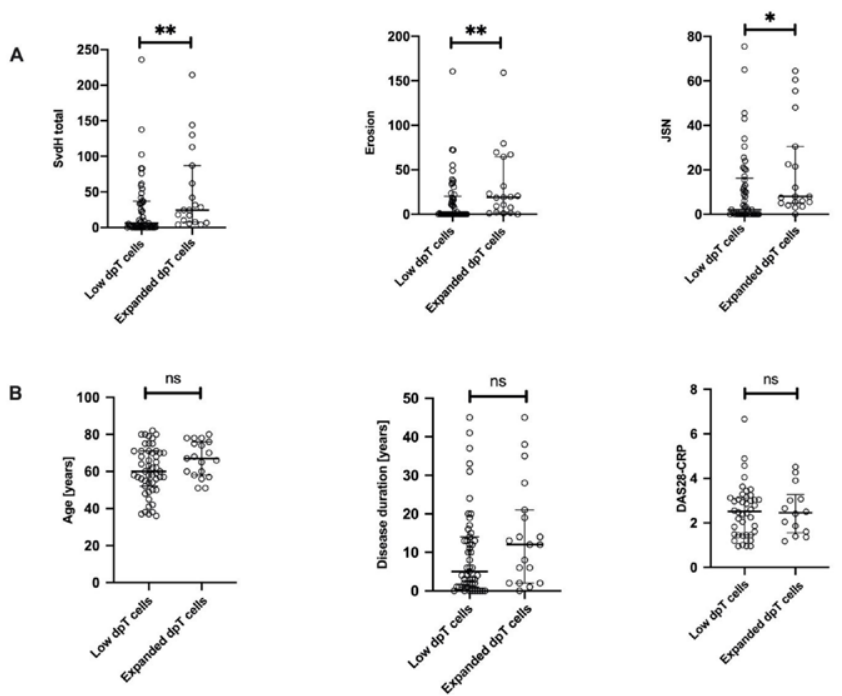

Figure 1. DpT cell expansion is associated with radiographic progression. $\mathrm{SvdH}$, modified Sharp/van der Heijde Score; DpT, $\mathrm{CD} 4^{+} / \mathrm{CD}^{+}$double-positive T cells.

Disclosure of Interests: None declared

DOI: 10.1136/annrheumdis-2021-eular.1533

\section{POS0383 EFFECTS OF TOFACITINIB THERAPY ON ARGININE AND METHIONINE METABOLITES IN ASSOCIATION WITH VASCULAR PATHOPHYSIOLOGY IN RHEUMATOID ARTHRITIS: A METABOLOMIC APPROACH}

B. Soós ${ }^{1}$, A. Hamar ${ }^{1}$, A. Pusztai ${ }^{1}$, M. Czókolyová ${ }^{1}$, E. Végh ${ }^{1}$, S. Szamosi ${ }^{1}$, Z. Pethöö, K. Gulyás ${ }^{1}$, G. Kerekes ${ }^{2}$, É. Szekanecz ${ }^{3}$, S. Szántó ${ }^{1}$, G. Szücs ${ }^{1}$ U. Christians ${ }^{4}$, J. Klawitter ${ }^{4}$, T. Seres $^{4}$, Z. Szekanecz ${ }^{1}{ }^{1}$ University of Debrecen, Rheumatology, Debrecen, Hungary; ${ }^{2}$ University of Debrecen, Medicine, Debrecen, Hungary; ${ }^{3}$ University of Debrecen, Oncology, Debrecen, Hungary; ${ }^{4}$ University of Colorado Anschutz Medical Campus, Anesthesiology, Aurora, CO, United States of America 